\title{
Physiological responses and animal behavior in Bonsmara-Hereford crosses vs. Hereford purebred on environment stress
}

\author{
Paula Alicia Batista Taborda ${ }^{*}$, Celmira Tomasina Saravia ${ }^{2}$, Ana Carolina Espasandin ${ }^{1}$
}

\author{
${ }^{1}$ University of the Republic of Uruguay/Faculty of Agriculture \\ - Dept. of Animal Production and Pastures, R. 3 km, 363 - \\ Paysandú - Uruguay. \\ 2University of the Republic of Uruguay/Faculty of Agriculture \\ - CENUR North Coast Salto, Rivera, 1350 - Salto - Uruguay. \\ *Corresponding author <pabt2508@gmail.com>
}

Edited by: Paulo Cesar Sentelhas

Received February 02, 2017

Accepted July 12, 2017

\begin{abstract}
Adaptative traits (rectal temperature-RT, respiratory rate-RR) and grazing behavior (Grazing, Ruminating and Rest time, and Sun or Shade time) of Bonsmara-Hereford crossbred$\mathrm{BH}, \mathrm{n}=15$, and purebred Hereford- $\mathrm{HH}, \mathrm{n}=18$, yearling heifers, in a grazing system of Uruguay. Environment characterization was made using $\mathrm{TH}_{\text {adiusted }}$ by radiation and wind speed (no, mild, and severe heat weaves), and the comprehensive climatic index-CCl (no, middle, moderate and severe stress). Adaptative traits were measured twice a day, weekly, in two consecutive days in summer and winter at $08 \mathrm{~h} 00$ and 16h00. Grazing behavior was observed from $07 \mathrm{~h} 00$ to $21 \mathrm{~h} 00$ each $600 \mathrm{~s}$ twice in summer. The records were analyzed using a mixed model. Significant effect of genotype was observed in mild heat waves for RR and RT in the afternoon (BH lower than $\mathrm{HH}$ ). For $\mathrm{CCl}$ in a.m., the RR was lower than $\mathrm{HH}$ in $\mathrm{BH}$ in severe stress, while in p.m., the RR was lower in all of $\mathrm{CCl}$ levels. RT in p.m. in moderate and severe was lower in $\mathrm{BH}$ than in $\mathrm{HH}$. In winter, no differences were found. In grazing behavior, $\mathrm{HH}$ rests longer than $\mathrm{BH}$ doe; also, $\mathrm{HH}$ spends more time in the shade (34 \%) than $\mathrm{BH}$ does (22\%). BH genotype showed better thermoregulation and grazing behavior at higher temperatures compared to $\mathrm{HH}$.
\end{abstract}

Keywords: beef cattle, grazing behavior, thermoregulation, bioclimatology

\section{Introduction}

Summer conditions under high environmental temperatures, relative humidity, solar radiation and low wind speed affect the physiology responses of cattle and its grazing behavior. As a result, animal welfare, forage intake, growth and daily gain are affected (Gaughan et al., 2008; Mader et al., 2006; Hahn, 1997).

Several alternatives have been proposed to mitigate heat stress in cattle, providing a suitable environment, natural shade, ventilation, etc., or using genetically adapted animals (Beede and Collier, 1986).

In northern Uruguay, the weather is variable, characterized by summers with high temperature and humidity, conditions can lead to heat stress in cattle as reported by Cruz and Saravia (2008) in dairy cows.

Generally, an index of temperature and humidity (THI) (Thom, 1959) is used to estimate heat stress in animals. New equations attached this index to wind speed and radiation lead to better fit beef cattle studies (Mader et al., 2006; Gaughan et al., 2008).

In beef and dairy breeds, several genetic resources have been selected for their adaptability to extreme climatic conditions, such as parasite resistance, heat tolerance, hardiness, and feed conversion efficiency (Frisch and Vercoe, 1992; 1979; Bonsma, 1980). The complementarities of different genotypes through crossbreeding can contribute to the adaptation of animals to different environments.

Bonsmara breed, a Bos taurus taurus biotype Sanga, also known as African Creole (Bonsma, 1980), is an example of adaptation to high temperature in African environment. This breed was introduced to Uruguay in 2005 and used in crossbred grazing systems.
This study evaluated the expression of adaptative, behavioral and growth traits in yearling Bonsmara-Hereford F1 crosses and contemporary purebred Hereford heifers, grazing natural pastures in northwestern Uruguay, during summer and winter.

\section{Materials and Methods}

The study was conducted in Paysandú, Uruguay $\left(32^{\circ} 2^{\prime} \mathrm{S}\right.$ latitude, $58^{\circ} 03^{\prime} \mathrm{W}$ longitude, $42 \mathrm{~m}$ above sea level). In this region, the mean temperatures in summer (Jan and Feb) average $24^{\circ} \mathrm{C}$ (maximum $41^{\circ} \mathrm{C}$ ) and relative humidity average $67 \%$, while the average temperature in winter (June and July) is $11^{\circ} \mathrm{C}$ (minimum $-4{ }^{\circ} \mathrm{C}$ ) and the relative humidity $80 \%$. Historical registers of total rainfall in Jan and Feb are $120 \mathrm{~mm}$ and in June and July is $70 \mathrm{~mm}$ (INUMET, 2015).

Variables of physiological responses and growth were measured in summer (Jan to Mar) and winter (June to Aug) while grazing behavior was measured in the summer.

\section{Weather characterization}

Daily data of recorded air temperature $\left(\mathrm{ta}^{\circ}{ }^{\circ} \mathrm{C}\right)$ and humidity $(\mathrm{RH}, \%)$, global solar radiation $\left(\mathrm{RAD}, \mathrm{W} \mathrm{m}^{2-1}\right)$ and wind speed at $2 \mathrm{~m}$ (WS, $\mathrm{m} \mathrm{s}^{-1}$ ) were recorded with an automatic weather station (EMA). Records of EMA were used to perform the temperature and humidity index (THI, Thom, 1959), the adjusted THI (THI ${ }_{\text {adjust }}$ ) and the comprehensive climatic index (CCI).

\section{Temperature and humidity index (THI)}

Daily and hourly EMA records of air temperature 
and humidity were used: THI $=(0.8 \times$ ta $+((\mathrm{RH} / 100)$ $\times($ ta -14.4$))+46.4$ (Thom, 1959; modified by Valtorta and Gallardo, 1996).

Temperature and humidity index adjusted by wind speed and radiation ( $\mathrm{THI}_{\text {adjust }}$ )

Using schedules and daily data on temperature, humidity, wind speed and radiation obtained from the EMA THI adjust $_{\text {was }}$ estimated (Mader et al., 2006).

$\mathrm{THI}_{\text {adjust }}$ hourly $=4.51+\mathrm{THI}-(1.992 \times \mathrm{WS})+(0.0068$ $\times$ RAD)

$\mathrm{THI}_{\text {adjust }}$ daily $=6.8+\mathrm{THI}-(3.075 \times \mathrm{WS})+(0.0114 \times$ RAD)

\section{Comprehensive climate index (CCI)}

The CCI is an index adjusted by air temperature, relative humidity, wind speed and solar radiation, to define environmental conditions (heat or cold). This index is more accurate to predict susceptibility of animals to environmental conditions. Other indices, such as THI do not integrate variables to define cold stress.

$\mathrm{CCI}=$ ta + Equations A $+\mathrm{B}+\mathrm{C}($ Mader et al., 2010).

Equation $\mathrm{A}=\mathrm{e}^{(0.00182 \times \mathrm{RH})+(1.8 \mathrm{e}-05 \times \mathrm{ta} \times \mathrm{RH}) \times}\left(\mathrm{ta}^{2} \times 0.000054\right)$ $+(0.00192 \times$ ta -0.0246$) \times(\mathrm{RH}-30)$

Equation $B=\left(-6.56 / \mathrm{e}^{((1 / 2.26 \times \mathrm{WS}+0.23) 0.45) \times(2.9+1.14 \times 10-6 \times \text { WS2.5- }}\right.$ $-\log 0.3(2.26 \times \mathrm{WS}+0.33)-2) \mid)-0.00566 \times \mathrm{WS}^{2}+3.33$

Equation $\mathrm{C}=0.0076 \times \mathrm{RAD}-0.00002 \times \mathrm{RAD} \times \mathrm{ta}+$ $0.00005 \times \mathrm{ta}^{2} \times \sqrt{ } \mathrm{RAD}+0.1 \times \mathrm{ta}-2$

\section{Heat weaves (HW)}

To define heat waves (abnormally warm and usually wet periods), the following criteria were used: $\rightarrow$ If for at least three consecutive days, THI > 74 for more than 14 consecutive hours (Cruz and Saravia, 2008). $\rightarrow$ If the average daily THI was $>74$ for three consecutive days or more, considering that the wave is not interrupted any day (of this 3) this threshold is not reached (Cruz and Saravia, 2008). They were classified into Severe Heat Wave (SHW) if both criteria were met, Mild Heat Wave (MHW) is defined if just one of both criteria are met. Days of No Heat Wave (NHW) are in the case of any criteria met (Cruz and Saravia, 2008). CCI ranges determine stress levels or animal susceptibility to heat and cold conditions as reported by Mader et al. (2010). In hot conditions, No stress level is observed when CCI < 25, Mild when $25<\mathrm{CCI}<30$, Moderate when $30<\mathrm{CCI}<35$, Severe $35<\mathrm{CCI}<40$, Extreme $40<\mathrm{CCI}<45$, and Danger when CCI > 45. In cold conditions, values for no stress, mild, moderate, severe, extreme and danger are for $\mathrm{CCI}>5,0>\mathrm{CCI}>5,0>$ $\mathrm{CCI}>-5,-5>\mathrm{CCI}>-10,-10>\mathrm{CCI}>-15$ and $\mathrm{CCI}$ $>-15$, respectively.

\section{Animals}

The measurements were made in 33 crossbred and purebred yearling heifers (15 Bonsmara-Hereford $(\mathrm{BH})$ and 18 purebred Hereford $(\mathrm{HH}))$. The heifers were contemporaries and managed in same conditions, grazing natural grasses of Uruguay.

\section{Physiological responses of cattle to heat stress}

Rectal temperature $(\mathrm{RT})$ and respiration rate $(\mathrm{RR})$ were recorded as physiological responses of heifers to weather conditions. Measurements were carried out in the morning and in the afternoon, in two consecutive days, weekly, during eight weeks, totalizing 30 measurements per heifer. The measurements were done at lower and higher air temperatures $107 \mathrm{~h} 00$ and 08h00 in summer and winter, respectively and $15 \mathrm{~h} 00$ and $16 \mathrm{~h} 00$, respectively). RT was recorded with a mercury thermometer $\left(0.1^{\circ} \mathrm{C}\right.$ accuracy) at the same time RR was recorded by $60 \mathrm{~s}$ observing the flank movements (number of breaths per minute) (Gaughan et al., 1999).

\section{Grazing behavior}

In summer, the grazing behavior was measured by observing 10 animals ( $5 \mathrm{HH}$ and $5 \mathrm{BH}$ ) for one day in two different moments of the experimental period. The location of each animal (in the Shade-Sh or Sun-Su) and its activity (Grazing-Gr, Ruminating-Ru or Rest-Re) were recorded each $600 \mathrm{~s}$ from sunrise (07h30) to sunset (20h00). Forage allowance (Table 1) was determined in summer by the double sampling method (Haydock and Shaw, 1975).

\section{Body weights (BW) and body condition scores (BCS)}

Every two weeks, the animals were weighted on an electronic scale (accuracy $=0.5 \mathrm{~kg}$ ) and BCS were recorded by visual appreciation using the validated scale by Vizcarra et al. (1986) for herds in Uruguay.

\section{Statistical analysis}

In summer and winter, RR and RT a.m. and p.m. were analyzed using a model of repeated measurements under a completely randomized design. The model contained the fixed effects of genotype, measurement day (includes HW in summer, or CCI levels in summer and winter) and the genotype $\times$ day interaction, and the cow ID as a random effect.

Table 1 - Availability and chemical composition of the forage.

\begin{tabular}{lcccccccc}
\hline $\begin{array}{l}\text { Experimental period } \\
\text { (summer) }\end{array}$ & $\mathrm{kg} \mathrm{DM} \mathrm{ha}^{-1}$ & $\mathrm{DM}$ & $\mathrm{A}$ & $\mathrm{CP}$ & $\mathrm{NDF}$ & $\mathrm{ADF}$ & $\mathrm{EE}$ \\
\cline { 3 - 8 } & & & & & $\%$ & & & \\
\hline Beginning & 373.6 & 94 & 13 & 8 & 67 & 32 & 3 \\
Middle & 500.2 & 93 & 12 & 7 & 69 & 33 & 4 \\
End & 388.3 & 94 & 13 & 8 & 69 & 32 & 3 \\
\hline
\end{tabular}

$\mathrm{DM}=$ dry matter; $\mathrm{A}=$ ash; $\mathrm{CP}=$ crude protein; NDF = Neutral detergent fiber; $\mathrm{ADF}=$ Acid detergent fiber; $\mathrm{EE}=$ ether extract. 
$y_{i j k}=\mu+G_{i}+\delta_{i j}+D_{k}+(G \times D)_{i k}+\varepsilon_{i j k}$

where: $y=\mathrm{RR}$ or, RT; $G_{i}=$ Genotype $(\mathrm{BH}, \mathrm{HH}) ; D_{k}=$ Day of measurement (SHW, MHW, NHW or CCI levels), $\left(G^{*} D\right)_{i k}=$ Genotype $\times$ Day of measurement; $\delta_{i j}=$ Random error $=0$ and variance $o^{2} \delta$ means, variance between animals (subject) within each genotype, equal to the covariance between repeated measurements on each animal, and $\varepsilon_{i j k}=$ Model error. The comparison of means was performed by orthogonal contrasts between genotypes and within each genotype each day of measurement.

To analyze BW and BCS, the model contained the fixed effects: genotype of the cow, moment measurement, genotype $\times$ moments interaction and the cow ID as a random effect.

$y_{i j k}=\mu+G_{i}+\delta_{i j}+M_{k}+(G \times M)_{i k}+\varepsilon_{i j k}$

where $y=\mathrm{BW}, \mathrm{BCS}, G_{i}=$ Genotype $(\mathrm{BH}, \mathrm{HH}), M_{k}$ $=$ Moments measurement (each 15 days from Dec to July), $\left(G^{*} M\right)_{i k}=$ Genotype $\times$ moments interaction, $\delta_{\mathrm{ij}}$ $=$ Random error $=0$ and variance $\sigma^{2} \delta$ means, variance between animals (subject) within each genotype, equal to the covariance between repeated measurements on each animal, and $\varepsilon_{\mathrm{ijk}}=$ Model error. ANOVA and half of least squares were analyzed by MIXED procedure in SAS (Statistical Analysis System, version 9.2) compared by the Tukey test set for each level of each significant $(p$ $<0.05)$.

For variable grazing behavior model contained the fixed effects genotype of the cow, moment measurement, genotype $\times$ moments interaction and the ID of the cow as a random effect.

$y_{i j k}=\mu+G_{i}+M_{j}+(G \times M)_{i j}+\varepsilon_{i j}$

where $y=\mathrm{Gr}, \mathrm{Ru}, \mathrm{Re}, \mathrm{Su}, \mathrm{Sh}, \mathrm{G}_{\mathrm{i}}=$ Genotype $(\mathrm{BH}$, $\mathrm{HH}$ ) $M_{j}=$ Moments measurement (2 times in summer), $\left(G^{*} M\right)_{i k}=$ Genotype $\times$ moments interaction, and $\varepsilon_{i j k}=$ Model error. ANOVAS and half of least squares were analyzed by MIXED procedure in SAS (Statistical Analysis System, version 9.2) compared by the Tukey test set for each level of significance $(p<0.05)$.

\section{Results}

\section{Meteorological conditions}

In summer (Jan to Mar), 68 days (78 \%) with MHW and emergency status for animal welfare $\left(\mathrm{THI}_{\text {adjust }}: 81 \pm\right.$ 4 aver.) and 19 days (22\%) without the presence of HW (THI adjust $: 69 \pm 3$ aver.) were detected. No SHW were detected during the summer period evaluated. Out of the 15 days when physiological responses were measured, nine days corresponded to MHW and six to NHW (Figure 1).

Also, if we characterize the meteorological conditions of summer and winter together, it is done through CCI as shown in Figure 2.

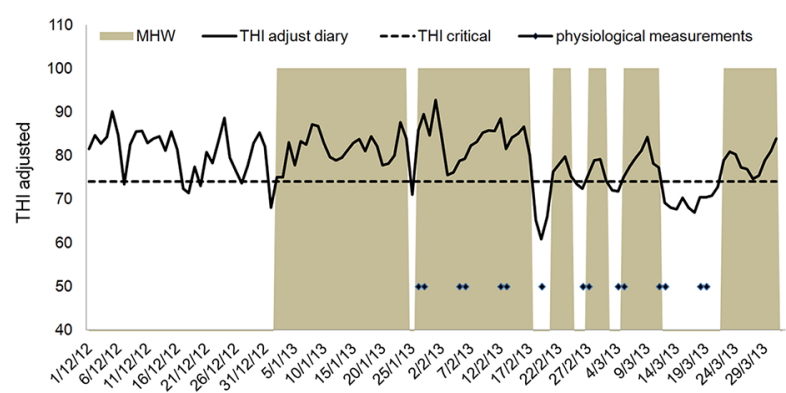

Figure 1 - Temperature and humidity index (THI) daily adjusted by radiation and wind speed (__ for the experimental period in summer (Jan to Mar), critical TH $<74(--)$, period of mild heat waves (MHW) (gray bars) and location of the days physiological measures (respiratory rate (RR), rectal temperature (RT) in black diamonds).

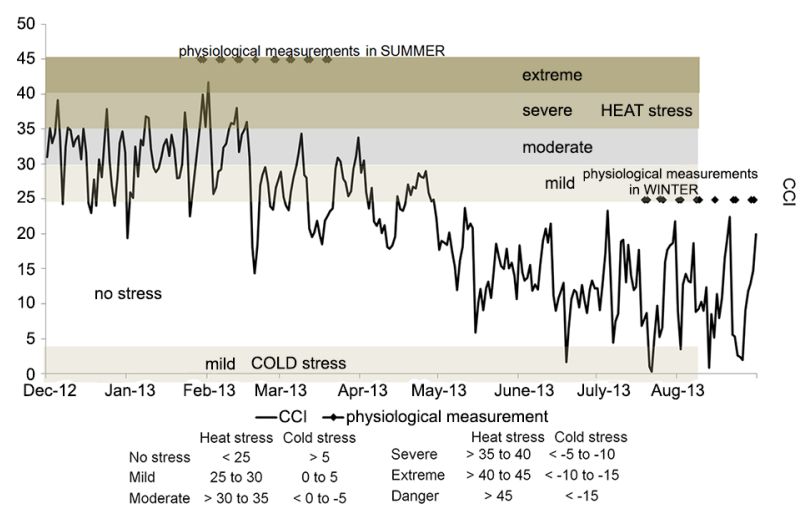

Figure 2 - Evolution of comprehensive climate index (CCl) during the experimental periods of summer and winter (_ $)$ indication of heat stress levels (extreme, severe, moderate, mild) and cold stress (mild), white space without stress in summer or winter, location of sampling dates physiological measures (RR and RT) in summer and winter.

In Figure 2, the entire experimental period is presented by the CCI per station, in summer (Dec to Feb) as many days showed moderate $(38 \%)$, mild $(24 \%)$ and severe stress (19\%), the physiological measurements were carried out in three days of severe stress, one with moderate stress, three with mild stress and two were performed on days without stress to the animals. In autumn (Mar to May), as expected, there were more days without stress for the animals (65\%), although $27 \%$ of the days were mild stress days when two measurements were made. In winter (June to Aug), there were $10 \%$ of days with mild cold stress, but most physiological measurements were made on days where no cold stress occurred.

\section{Body weight and body condition score}

No significant difference in BW between genotypes (Figure 3) was found ( $p>0.05)$. Regarding BCS (Figure 4), significant differences between genotypes in summer (Feb) and winter (July and Aug) were found, with higher values for $\mathrm{BH}$ compared to $\mathrm{HH}$. 


\section{Physiological response}

The results of $\mathrm{RR}$ and $\mathrm{RT}$ in $\mathrm{BH}$ and $\mathrm{HH}$ analyzed according to weather conditions (MHW, NHW) in summer and time of measurement (a.m. or p.m.) are shown in Table 2.

In summer, in the afternoon, in records in MHW, $\mathrm{HH}$ was significantly higher than to $\mathrm{BH}$ in $\mathrm{RR}$ (58.4 \pm 1.7 vs. $45.8 \pm 2.8 \mathrm{bpm}, p=0.0007)$. Also, $\mathrm{HH}$ was higher in $\mathrm{RT}$ in the same records $\left(39.5 \pm 0.04{ }^{\circ} \mathrm{C}\right)$ than $\mathrm{BH}$ $\left(39.2 \pm 0.06{ }^{\circ} \mathrm{C}\right)(p=0.0003)$ (Table 2$)$.

In Table 3, in summer, for CCI in a.m., the RR was significantly lower in $\mathrm{BH}(33.7 \pm 1.6 \mathrm{bpm})$ than $\mathrm{HH}$ $(39.5 \pm 1.0 \mathrm{bpm})(p=0.029)$ in severe stress, and in moderate stress, $\mathrm{BH}(33.5 \pm 1.8 \mathrm{bpm})$ was lower than $\mathrm{HH}(37.6 \pm 1.0 \mathrm{bpm})(p=0.05)$.

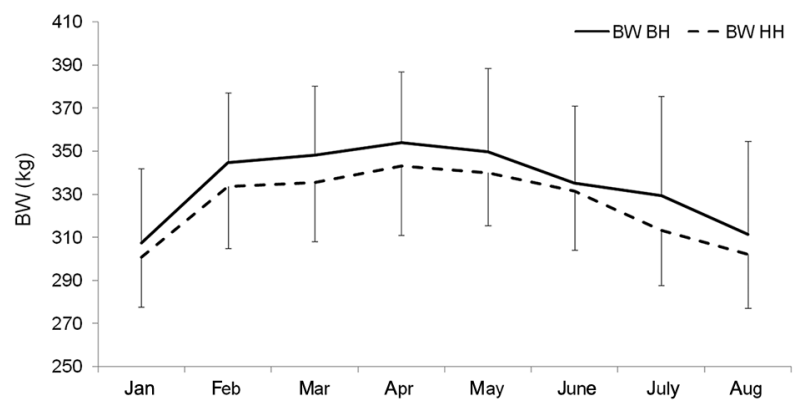

Figure 3 - Body weight (BW) of genotypes cross Bonsmara-Hereford $(\mathrm{BH})$ and purebred Hereford $(\mathrm{HH})$ in the experimental period.

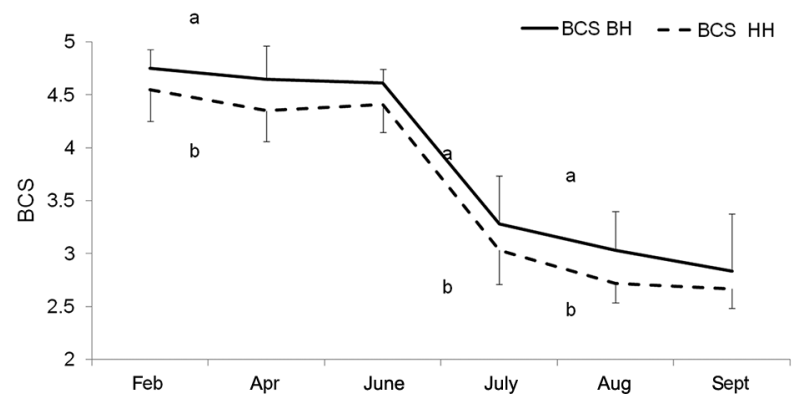

Figure 4 - Body condition score (BCS) of genotypes cross Bonsmara-Hereford $(\mathrm{BH})$ and purebred Hereford $(\mathrm{HH})$ in the experimental period.
While in p.m., RR was lower than $\mathrm{HH}$ in $\mathrm{BH}$ heifers in all CCI levels $(p<0.0001)$. RT in a.m. was significantly lower in $\mathrm{BH}\left(38.5 \pm 0.04^{\circ} \mathrm{C}\right)$ than $\mathrm{HH}(38.6$ $\left.\pm 0.02{ }^{\circ} \mathrm{C}\right)(p=0.02)$ in mild stress. In severe stress, $\mathrm{BH}$ was significantly lower $\left(38.95 \pm 0.06{ }^{\circ} \mathrm{C}\right)$ than $\mathrm{HH}$ $\left(39.11 \pm 0.04^{\circ} \mathrm{C}\right)$. In p.m., $\mathrm{BH}$ was lower in moderate $\left(39.3 \pm 0.11^{\circ} \mathrm{C}\right)$ vs. $\mathrm{HH}(39.7 \pm 0.07)(p=0.0014)$, and in severe $\mathrm{BH}(39.4 \pm 0.11)$ and $\mathrm{HH}(39.9 \pm 0.07)(p<$ $0.0001)$.

In Table 4, in winter, no significant differences were observed in CCI levels between genotypes in physiological responses.

\section{Animal behavior}

The Figure 5 presents the variation in THI and CCI 6 days before each behavior observations.

As shown in Figure 5, during the observation of behavior in grazing heifers, THI adjusted reached values of 82.3 and CCI was 32.4. In the second observation of behavior, THI and CCI were lower $(79.5$ and $29.8 \mathrm{THI}$ and $\mathrm{CCI}$, respectively), but both observations indexes were above critical levels as mentioned in the bibliography THI = 74 (Mader et al., 2006), and CCI = 25 (Mader et al., 2010).

Figures 6 and 7 show the percentage of the time spent in grazing behavior (grazing, ruminating or rest,

Table 2 - Last squares means of physiological response (respiration rate-RR and rectal temperature-RT) in summer by time measurement (a.m. and p.m.), weather conditions (days of no heat wave (NHW) and mild heat wave (MHW)) and genotype BonsmaraHereford-BH and Hereford pure-HH.

\begin{tabular}{|c|c|c|}
\hline \multirow{4}{*}{$\begin{array}{l}\text { Weather } \\
\text { condition and } \\
\text { Variable }\end{array}$} & \multicolumn{2}{|c|}{ Time of measurement at day } \\
\hline & \multirow{2}{*}{$\begin{array}{c}\text { a.m. } \\
\text { Genotypes }\end{array}$} & \multirow{2}{*}{$\begin{array}{c}\text { p.m. } \\
\text { Genotypes }\end{array}$} \\
\hline & & \\
\hline & $\mathrm{BH} \quad \mathrm{HH}$ & $\mathrm{BH} \quad \mathrm{HH}$ \\
\hline \multicolumn{3}{|l|}{$\mathrm{NHW}$} \\
\hline RR (bpm) & $28.0 \pm 1.629 .4 \pm 1.0 \quad N S$ & $31.4 \pm 2.9 \quad 38.6 \pm 1.8 \quad \mathrm{NS}$ \\
\hline $\mathrm{RT}\left({ }^{\circ} \mathrm{C}\right)$ & $38.6 \pm 0.0638 .6 \pm 0.04 \mathrm{NS}$ & $38.9 \pm 0.0739 .0 \pm 0.04 \mathrm{NS}$ \\
\hline \multicolumn{3}{|c|}{ e } \\
\hline RR (bpm) & $30.3 \pm 1.3 \quad 33.8 \pm 0.8$ NS & $45.8 \pm 2.8 \quad 58.4 \pm 1.7 \quad$ * \\
\hline $\mathrm{RT}\left({ }^{\circ} \mathrm{C}\right)$ & $38.6 \pm 0.0538 .8 \pm 0.03 \mathrm{NS}$ & $39.2 \pm 0.0639 .5 \pm 0.04$ * \\
\hline
\end{tabular}

Table 3 - Last squares means of physiological response (respiration rate-RR and rectal temperature-RT) in summer by levels of comprehensive climatic index (CCl) time measurement (a.m. and p.m.) and genotype Bonsmara-Hereford (BH) and Hereford pure (HH).

\begin{tabular}{|c|c|c|c|c|c|c|c|c|c|}
\hline \multirow{2}{*}{\multicolumn{2}{|c|}{ Summer }} & \multicolumn{8}{|c|}{ CCl levels } \\
\hline & & \multicolumn{2}{|c|}{ No Stress } & \multicolumn{2}{|c|}{ Mild Stress } & \multicolumn{2}{|c|}{ Moderate Stress } & \multicolumn{2}{|c|}{ Severe Stress } \\
\hline \multirow{2}{*}{ Time } & \multirow{2}{*}{ Variable } & \multicolumn{8}{|c|}{ Genotypes } \\
\hline & & $\mathrm{BH}$ & $\mathrm{HH}$ & $\mathrm{BH}$ & $\mathrm{HH}$ & $\mathrm{BH}$ & $\mathrm{HH}$ & $\mathrm{BH}$ & $\mathrm{HH}$ \\
\hline \multirow[b]{2}{*}{ a.m. } & $\mathrm{RR}$ (bpm) & $28.0 \pm 1.2 \mathrm{NS}$ & $29.4 \pm 0.7 \mathrm{NS}$ & $28.2 \pm 1.1 \mathrm{NS}$ & $29.9 \pm 0.7 \mathrm{NS}$ & $33.5 \pm 1.8^{*}$ & $37.6 \pm 1.0^{*}$ & $33.8 \pm 1.6^{*}$ & $39.5 \pm 1.0^{*}$ \\
\hline & $\mathrm{RT}\left({ }^{\circ} \mathrm{C}\right)$ & $38.5 \pm 0.04 \mathrm{NS}$ & $38.56 \pm 0.03 \mathrm{NS}$ & $38.5 \pm 0.04^{*}$ & $38.6 \pm 0.02^{*}$ & $38.8 \pm 0.1 \mathrm{NS}$ & $38.9 \pm 0.04 \mathrm{NS}$ & $38.9 \pm 0.1^{*}$ & $39.1 \pm 0.04^{*}$ \\
\hline \multirow{2}{*}{ p.m. } & $\mathrm{RR}(\mathrm{bpm})$ & $31.4 \pm 2.1^{*}$ & $38.6 \pm 1.3^{*}$ & $39.9 \pm 2.0$ * & $49.5 \pm 1.2^{*}$ & $49.0 \pm 2.9^{\star}$ & $68.1 \pm 1.8^{*}$ & $57.3 \pm 2.9^{*}$ & $70.7 \pm 1.8^{*}$ \\
\hline & $\mathrm{RT}\left({ }^{\circ} \mathrm{C}\right)$ & $38.8 \pm 0.1 \mathrm{NS}$ & $39.0 \pm 0.05 \mathrm{NS}$ & $39.1 \pm 0.07 \mathrm{NS}$ & $39.2 \pm 0.04 \mathrm{NS}$ & $39.3 \pm 0.1^{*}$ & $39.7 \pm 0.1^{*}$ & $39.4 \pm 0.1^{*}$ & $39.9 \pm 0.1^{*}$ \\
\hline
\end{tabular}

Contrast genotypes by each CCl level; ${ }^{*} p<0.05$; NS $=$ not statistically significant. 
Table 4 - Last squares means of physiological response (respiration rate-RR and rectal temperature-RT) in winter by levels of comprehensive climatic index (CCl) time measurement (a.m. and p.m.) and genotype Bonsmara-Hereford (BH) and Hereford pure (HH).

\begin{tabular}{|c|c|c|c|c|c|}
\hline \multirow{2}{*}{ Winter } & & \multicolumn{4}{|c|}{ CCI levels } \\
\hline & & \multicolumn{2}{|c|}{ No Stress } & \multicolumn{2}{|c|}{ Mild Stress } \\
\hline \multirow{2}{*}{ Time } & \multirow{2}{*}{ Variable } & \multicolumn{4}{|c|}{ Genotypes } \\
\hline & & $\mathrm{BH}$ & $\mathrm{HH}$ & $\mathrm{BH}$ & $\mathrm{HH}$ \\
\hline \multirow{2}{*}{ a.m. } & RR (bpm) & $21.5 \pm 1.4 \mathrm{NS}$ & $24.1 \pm 0.8 \mathrm{NS}$ & $16.7 \pm 2.8 \mathrm{NS}$ & $17.7 \pm 1.7 \mathrm{NS}$ \\
\hline & $\mathrm{RT}\left({ }^{\circ} \mathrm{C}\right)$ & $38.3 \pm 0.2 \mathrm{NS}$ & $38.8 \pm 0.04 \mathrm{NS}$ & $38.3 \pm 0.2$ NS & $38.4 \pm 0.1 \mathrm{NS}$ \\
\hline \multirow{2}{*}{ p.m. } & RR (bpm) & $23.7 \pm 1.4 \mathrm{NS}$ & $26.4 \pm 0.8 \mathrm{NS}$ & & \\
\hline & $\mathrm{RT}\left({ }^{\circ} \mathrm{C}\right)$ & $38.9 \pm 0.05 \mathrm{NS}$ & $39.0 \pm 0.03 \mathrm{NS}$ & & \\
\hline
\end{tabular}

Contrast genotypes by each CCl level; ${ }^{*} p<0.05=\mathrm{NS}=$ not statistically significant.

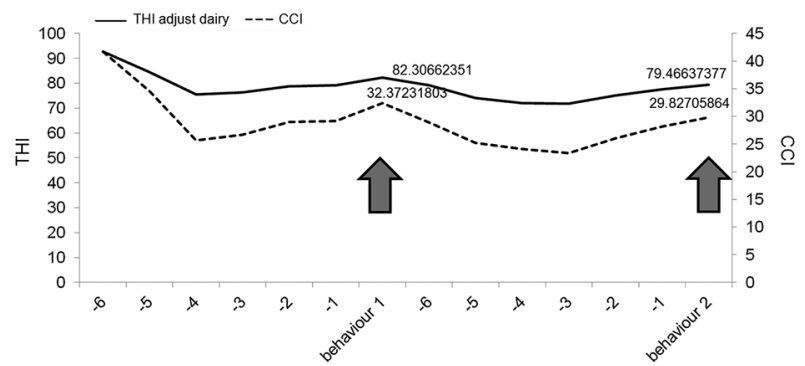

Figure $\mathbf{5}$ - TH - temperature and humidity index adjusted daily (__ ) and $\mathrm{CCl}$ - comprehensive climate index (- - ) evolution 6 days prior to dates grazing behavior of animals (behavior $1=7$ Feb, behavior 2 = Mar 7).

and in the sun or in the shade) of $\mathrm{HH}$ and $\mathrm{BH}$ heifers in two moments of the summer experimental period.

Figure 8 presents the average in percent of total grazing between genotypes.

$\mathrm{HH}$ and $\mathrm{BH}$ heifers had no significant differences in the grazing time $(p=0.35)$, nor in the rumination time $(p=0.33)$. By contrast, differences were observed in rest time, where the crosses $\mathrm{BH}$ rested less $16480 \pm$ $636 \mathrm{~s}, 13 \%)$ compared to pure $\mathrm{HH}(8460 \pm 636 \mathrm{~s}, 18 \%)$ $(p=0.04)$.

Significant differences for time spent in the sun and in the shade were observed, were $\mathrm{BH}$ remains longer in the sun $(36600 \pm 1220.4 \mathrm{~s}, 77 \%)$ than $\mathrm{HH}(31620$ $\pm 1220.4 \mathrm{~s}, 66 \%)(p=0.01)$. Similarly, HH spent more time in the shade $(16080 \pm 1236 \mathrm{~s}, 34 \%)$ than $\mathrm{BH}$ did $(10920 \pm 1236 \mathrm{~s}, 23 \%)(p=0.009)$. Significant differences in rest time were observed with $8460 \pm 636 \mathrm{~s}$ in $\mathrm{HH}$ and $6480 \pm 636 \mathrm{~s}$ in $\mathrm{BH}$ heifers, $p=0.04$. There were no significant differences between $\mathrm{BH}$ and $\mathrm{HH}$ in total $\mathrm{Gr}$ and $\mathrm{Ru}$, but in $\mathrm{Re}, \mathrm{HH}$ rested longer than $\mathrm{BH}$ did. In addition, BH genotype showed better performance in body weight and body condition score, thermoregulation and grazing behavior at higher temperatures compared to $\mathrm{HH}$ animals.

\section{Discussion}

In this study, we found a marked effect on how the environment affects animal welfare. Exposure of differ-
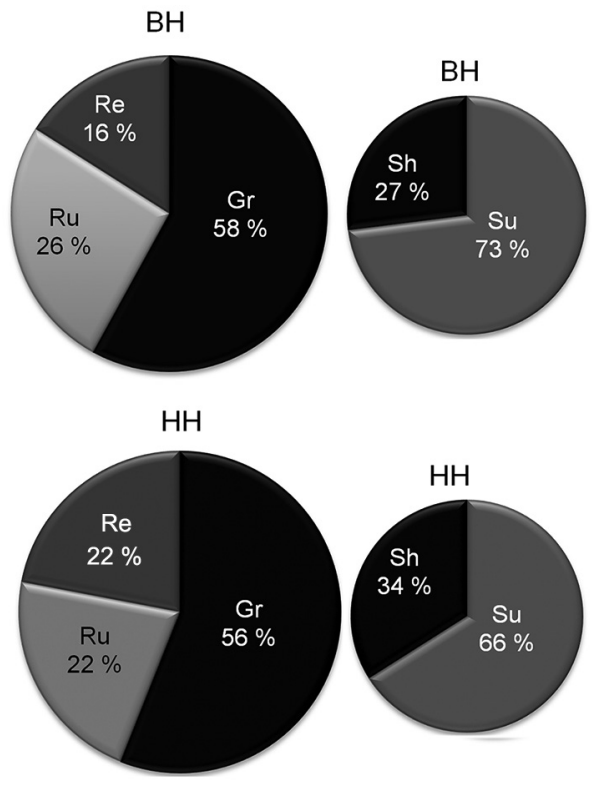

Figure 6 - Behavior 1: Proportion of time in percentage (\%) used by both genotypes, Hereford pure $(\mathrm{HH})$ and Bonsmara-Hereford $(\mathrm{BH})$ adapted to each activity $(\mathrm{Gr}=$ time grazing, $\mathrm{Ru}=$ ruminating time, $\mathrm{Re}=$ rest time) and location (in the shade (Sh) or sun (Su)).

ent genotypes ( $\mathrm{BH}$ and $\mathrm{HH})$ to high temperatures resulted in different physiological and behavioral responses. To quantify the effect produced by climate on animals is essential use of biometeorological indices, such as CCI (Mader et al., 2010), which provides an adjusted value to air temperature, relative humidity, wind speed and radiation under conditions of heat or cold. This index incorporates the climatic effects affecting the body surface of the animal, indicating the level at which it is possible or not to generate a heat exchange between the animal and the environment.

Physiological responses of cattle against weather conditions in the northern region of Uruguay show that $\mathrm{BH}$ crosses have more tolerance to high temperatures in the presence of waves of mild heat and at all levels of $\mathrm{CCI}$ in summer for $\mathrm{HH}$.

Similar results were reported by Bonsma (1980) in 


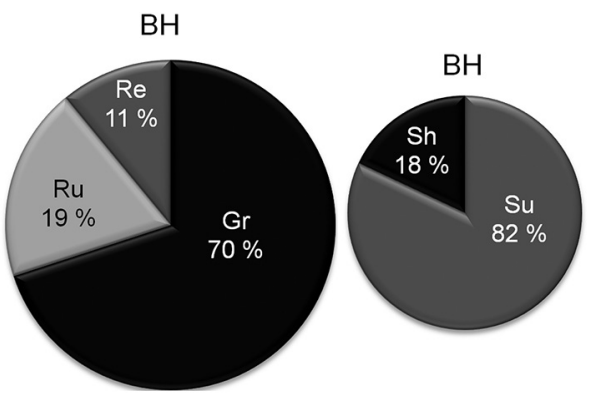

$\mathrm{HH}$

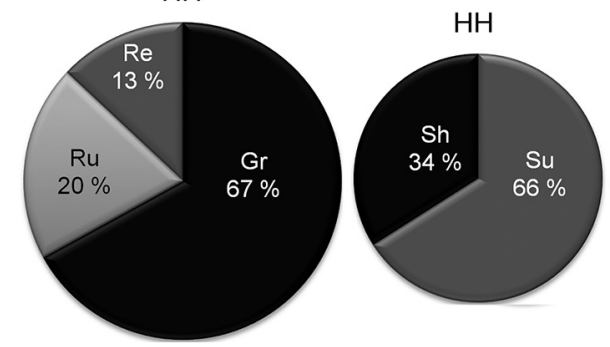

Figure 7 - Behavior 2: Proportion of time in percentage (\%) used by both genotypes Hereford pure $(\mathrm{HH})$ and Bonsmara-Hereford $(\mathrm{BH})$ adapted to each activity ( $\mathrm{Gr}=$ time grazing, $\mathrm{Ru}=$ ruminating time, $\mathrm{Re}=$ rest time) and location (in the shade (Sh) or sun (Su)).

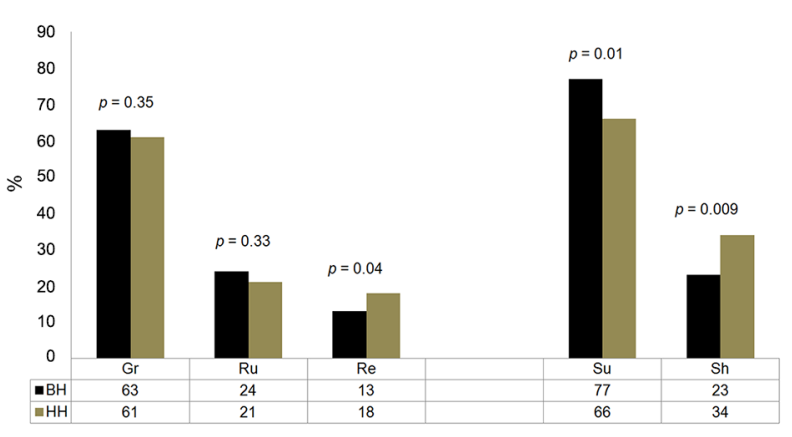

Figure 8 - Average grazing behavior between behaviors 1 and 2. Proportion of time in percentage (\%) used by both genotypes Hereford pure $(\mathrm{HH})$ and Bonsmara-Hereford $(\mathrm{BH})$ adapted to each activity ( $\mathrm{Gr}=$ time grazing, $\mathrm{Ru}=$ ruminating time, $\mathrm{Re}=$ rest time) and location (in the shade (Sh) or sun (Su)).

a comparative study on British cattle of origin, Afrikaner, and their crosses in the southafrican savannah. These genotypes were exposed to air temperatures between 32 to $37^{\circ} \mathrm{C}$ and physiological responses were measured. As a result, the Afrikaner-British cross had lower respiratory rate per minute (ranges from 30 to $50 \mathrm{bpm}$ ) and stable body temperatures between 38 and $39{ }^{\circ} \mathrm{C}$. Pure British had high respiratory rates (50-100 bpm), clearly emphasizing that the British genotypes at high environment temperatures, heat stress symptoms by increasing respiratory rate, are unable to mitigate this effect.

Hammond et al. (1996) in Florida, the United States, measured RR and RT in Senepol, Romosinuano, Brahman, Aberdeen Angus and Hereford heifers during summer and found similar results. The first three breeds presented higher ability to keep RT around $39{ }^{\circ} \mathrm{C}$ while Aberdeen Angus and Hereford reached $40.3^{\circ} \mathrm{C}$. RF was lower in Brahman (36 $\pm 2.4 \mathrm{rpm}$ ), Romosinuano (55 \pm $2.6 \mathrm{rpm})$ and Senepol (57 $\pm 3.1 \mathrm{rpm})$, and higher in Aberdeen Angus (69 $\pm 1.9 \mathrm{rpm}$ ) and Hereford (64 \pm 3.6 rpm).

There is clearly a greater capacity of crossbreeding in trying to mitigate the effect of heat stress. To moderate and severe stress and in the presence of waves of mild heat, genotype $\mathrm{HH}$ fails to mitigate climate effects or makes a lesser degree than heifer crosses do, because it has high RR and RT compared to BH. Moreover, Brosh et al. (1998) reported that against a heat stress in the animal, body heat is not lost, it tends to accumulate and thus an increase in body temperature occurs. Frisch and Vercoe (1992) indicated that the effect of an increase in RT is similar for all breeds, but it is strongly influenced by the environment temperature. The authors highlight that for the same environmental temperature of $25^{\circ} \mathrm{C}$, genotypes pure Brahman and crossed Hereford-Shorthorn showed the same RT $\left(38^{\circ} \mathrm{C}\right)$. However, when the air temperature rises to $35^{\circ} \mathrm{C}$, crossed animals raise their RT, while the pure Brahman continues with this constant.

In this work, in high air temperatures (i.e. in MHW and all levels of CCI), HH had more than 13 franqueal movement counts (bpm) compared to BH crosses. $\mathrm{HH}$ also had significant higher $\mathrm{RT}$ in relation to $\mathrm{BH}$.

In grazing behavior, $\mathrm{BH}$ grazed more minutes in the sun than in the shade compared to $\mathrm{HH}$. These results are similar to those reported by Bennett et al. (1985), who determined grazing time and behavior of Brahman steers, Shorthorn and Brahman $\times$ Hereford. In these observations, genotype Shorthorn spends more time (12528 s daily) in shade and Brahman less (5904 s daily).

Forbes et al. (1998) in Texas, the United States, (Heat index: $25{ }^{\circ} \mathrm{C}$ ) reported similar results observing rest time in shadowing from genotypes Angus, Brahman, Angus-Brahman cross $(\mathrm{A} \times \mathrm{B})$, Tuli-Brahman $(\mathrm{T}$ $\times$ B). Between 9 a.m. and 5 p.m., Angus spent more time resting in shade (72000 s daily), while Brahman and crosses, which are more adapted to the heat, spent less time (43200 s daily). However, the authors found statistical differences in grazing time, where Aberdeen Angus grazed less time $(23880 \pm 924$ s daily) than crosses $\mathrm{A} \times \mathrm{B}(30420 \pm 1104 \mathrm{~s}$ daily) and $\mathrm{T} \times \mathrm{B}$ (31320 \pm 1008 s daily), while Brahman grazes more time (33600 \pm 1008 s daily).

Some Bos taurus breeds are alternative sources of germplasm that present characteristics of adaptation to warm environments, which, in current and future times, should be considered by the recurring impact of climate change. The Bonsmara breed is one of them, which is reared to perform adaptation to high temperature climates, without losses in reproduction and production indexes. 
The results obtained in this experiment show that the $\mathrm{BH}$ crosses have higher thermoregulation capacity compared to pure Hereford cattle.

Although the experiment was conducted for a year, a normal year in climatological terms, $\mathrm{BH}$ crosses presented more adaptation and better productive results, showing higher live weight and body condition scores, as well as lower RF and RT during the summer than $\mathrm{HH}$ did.

In cold environments, changes in animals are observed in increased metabolic rate thus increased maintenance energy requirement and increased rate of passage of digestion, resulting in reduced digestive efficiency.

In winter, both genotypes respond favorably to environmental conditions while they keep RR and RT. However, the tendency of $\mathrm{BH}$ to keep lower respiratory rates to maintain higher internal temperatures. In addition, $\mathrm{BH}$ also achieved better conditions and body weights in this season, compared to Hereford.

\section{Conclusions}

The expression of adaptation to heat conditions, especially in the presence of heat waves, is represented by the animal ability to keep constant (or within normal ranges) $\mathrm{RR}$ and $\mathrm{BT}$. Under these observations, $\mathrm{BH}$ heifers seem to show more tolerance to environmental stress conditions, compared to $\mathrm{HH}$. On the other hand, in winter, there were no significant differences in physiological variables, showing a slightly better performance in $\mathrm{BH}$. $\mathrm{BH}$ heifers grazed longer in the sun and rested less compared to $\mathrm{HH}$ heifers.

\section{Acknowledgment}

To School of Agronomy, and School of Veterinary, from University of Republic, Uruguay.

To Bach José Victor Isola by contribution in English translation.

\section{References}

Beede, D.; Collier, R. 1986. Potential nutritional strategies for intensively managed cattle during thermal stress. Journal of Animal Science 62: 543-554.

Bennett, I.; Finch, V.; Holmes, C. 1985. Time spent in shade and its relationship with physiological factors of thermoregulation in three breeds of cattle. Applied Animal Behavior Science 13: 227-236.
Bonsma, J. 1980. Livestock Production: A Global Approach. Tafelberg, Cape Town, South Africa.

Brosh, A.; Aharoni, Y.; Degen, A.; Wright, D.; Young, B. 1998. Effects of solar radiation, dietary energy, and time of feeding on thermoregulatory responses and energy balance in cattle in a hot environment. Journal of Animal Science 76: 2671- 2677.

Cruz, G.; Saravia, C. 2008. Air temperature and humidity index for regionalization of dairy farming in Uruguay. Agrociencia 12: 56-60 (in Spanish, with abstract in English).

Forbes, T.; Rouquette, F.; Holloway, J. 1998. Comparisons among Tuli-, Brahman-, and Angus-Sired Heifers: intake, digesta kinetics and grazing behavior. Journal of Animal Science 76: 220-227.

Frisch, J.; Vercoe, J. 1979. Adaptative and productive features of cattle growth in the tropics: their relevance to buffalo production. Tropical Animal Production 4: 214-222.

Frisch, J.; Vercoe, J. 1992. Genotype (breed) and environment interaction with particular reference to cattle in the tropics. Asian-Australasian Journal of Animal Sciences 5: 401-409.

Gaughan, J.; Mader, T.; Holt, S.; Josey, M.; Rowan, K. 1999. Heat tolerance of Boran and Tuli crossbred steers. Journal of Animal Science 77: 2398-2405

Gaughan, J.; Mader, T.; Holt, S.; Lisle, A. 2008. A new heat load index for feedlot cattle. Journal of Animal Science 86: 226-234.

Hahn, G. 1997. Dynamic responses of cattle to thermal heat loads. Journal of Animal Science 77: 10-20.

Hammond, A.; Olson, T.; Chase, C.; Bowers, E.; Randel, R.; Murphy, C.; Vogt, D.; Tewolde, A. 1996. Heat tolerance in two tropically adapted Bos Taurus breeds, Senepol and Romosinuano, compared with Brahman, Angus and Hereford cattle in Florida. Journal of Animal Science 74: 295-303.

Haydock, K.; Shaw, N. 1975. The comparative yield method for estimating dry matter yield of pasture. Australian Journal of Experimental Agriculture and Animal Husbandry 15: 663-670.

Instituto Uruguayo de Meteorología [INUMET]. 2015. Uruguayan Institute of Meteorology = Instituto Uruguayo de Meteorología. Available at: http://www.meteorologia.com.uy/ [Accessed June 18, 2015] (in Spanish).

Mader, T.; Davis, M.; Brown-Brandl, T. 2006. Environmental factors influencing heat stress in feedlot cattle. Journal of Animal Science 84: 712-719.

Mader, T.; Johnson, L.; Gaughan, J. 2010. A comprehensive index for assessing environmental stress in animals. Journal of Animal Science 88: 2153-2165.

Thom, E. 1959. The discomfort index. Weatherwise 12: 57-59.

Valtorta, S.; Gallardo, M. 1996. Heat stress in dairy production = El estrés por calor en producción lechera. Instituto Nacional de Tecnología Agropecuaria. Miscelánea 81: 173-185 (in Spanish).

Vizcarra, J.; Ibañez, W.; Oscasberro, R. 1986. Repeatability and reproducibility of two scales to estimate body condition of cows Hereford. Agronomic Research 7: 45-47. 